\title{
Operation of Design Review in Small Irrigation Projects in Dang Valley of Nepal
}

\author{
Amrit Kumar Dahal *, A. K. Mishra **, \& P. S. Aithal *** \\ * Engineer, Province Government, Province No. 1, Infrastructure Development Office, \\ Bhojpur, Nepal. \\ E-mail: ami10_25@hotmail.com \\ ** Post-Doctoral Research Scholar, Srinivas University, India and Associate Professor, \\ Madan Bhandari Memorial Academy Nepal, Urlabari3, Morang, Nepal. \\ OrcidID: 0000-0003-2803-4918; Email: anjaymishra2000@ gmail.com \\ *** Professor, College of Management \& Commerce, Srinivas University, Mangalore, India. \\ OrcidID: 0000-0002-4691-8736; E-mail: psaithal@gmail.com
}

Area of the Paper: Project Management.

Type of the Paper: Action Research.

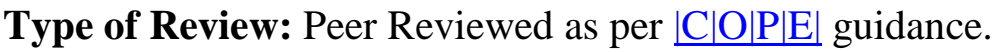

Indexed In: OpenAIRE.

DOI: https://doi.org/10.5281/zenodo.6331334

Google Scholar Citation: $\underline{\text { IJCSBE }}$

\section{How to Cite this Paper:}

Dahal, Amrit Kumar., Mishra, A. K., \& Aithal, P. S. (2022). Operation of Design Review in Small Irrigation Projects in Dang Valley of Nepal. International Journal of Case Studies in Business, IT, and Education (IJCSBE), 6(1), 139-157. DOI: https://doi.org/10.5281/zenodo.6331334

International Journal of Case Studies in Business, IT and Education (IJCSBE)

A Refereed International Journal of Srinivas University, India.

Crossref DOI : https://doi.org/10.47992/IJCSBE.2581.6942.0156

Paper Submission: 16/02/2022

Paper Publication: 07/03/2022

(C) With Authors.

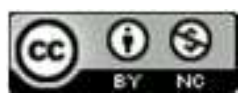

This work is licensed under a Creative Commons Attribution Non-Commercial 4.0 International License subject to proper citation to the publication source of the work.

Disclaimer: The scholarly papers as reviewed and published by the Srinivas Publications (S.P.), India are the views and opinions of their respective authors and are not the views or opinions of the S.P. The S.P. disclaims of any harm or loss caused due to the published content to any party. 


\title{
Operation of Design Review in Small Irrigation Projects in Dang Valley of Nepal
}

\author{
Amrit Kumar Dahal*, A. K. Mishra**, \& P. S. Aithal*** \\ *Engineer, Province Government, Province No. 1, Infrastructure Development Office, \\ Bhojpur, Nepal. \\ E-mail: ami10_25@hotmail.com \\ **Post-Doctoral Research Scholar, Srinivas University, India and Associate Professor, \\ Madan Bhandari Memorial Academy Nepal, Urlabari3, Morang, Nepal. \\ OrcidID: 0000-0003-2803-4918; Email: anjaymishra2000@ gmail.com \\ *** Professor, College of Management \& Commerce, Srinivas University, Mangalore, India. \\ OrcidID: 0000-0002-4691-8736; E-mail: psaithal@gmail.com
}

\begin{abstract}
Purpose: Farmer Managed Irrigation Systems (FMIS) in Nepal are pioneers because of their traditional practice leading to sustainability and its efficient operating systems for centuries. In the context of the modernization of FMIS, it is important to preserve the traditional sustainable design approach along with its new construction techniques. This research has attempted to reveal the practices of design review.

Design/Methodology/Approach: To meet these objectives primary and secondary data were collected in fifteen surface irrigation schemes developed by CIP in Dang Valley. A questionnaire survey and observations were done to collect primary data followed by a collection of Feasibility Assessment Report as secondary data. Descriptive analysis was done using graphs and tables whenever applicable along with supported by a literature review.

Findings/Result: The study found that farmers' participation in project selection and the detailed survey was satisfactory. The project cost has always been seen as a burning issue during planning, design, and implementation. $89 \%$ of respondents agreed that the budget ceiling in the project affected design. Overall, $72 \%$ of respondents opined that the proposed design is not sufficient for implementation which indicates that there is a need for design review, particularly for sustainability and efficient system. The study revealed that the gap between the design and construction phase could be minimized by revising the design and checking its compliance with actual site conditions before its implementation. The practice of design was found to be a very preliminary stage by the client.
\end{abstract}

Originality/Value: The design of the project assures the constructability and performance of the project. So, the study signifies the pioneer sector FMIS to be constructed without any design issue through the documented practice of design review. The study has intended to study to minimize the gap between the design and construction phase.

Paper Type: Action Research

Keywords: Status, Planning, Budget, Gap, Perception survey

\section{INTRODUCTION :}

Nepal has approximately a 2.641million Ha of agricultural land. Out of that 1.76 million Ha of land can be irrigated using various surface and groundwater irrigation methods. By the end of the fiscal year 2015/16, 1.396 million Ha of land has been irrigated (NPC, 2015) [1]. So effective irrigation design and management are essential for the sustainability of the system. Irrigation projects have to undergo detailed planning and design process before they are implemented (DoI, 2006) [2]. Generally, survey and design work is awarded to consultants, and construction work is done either by a contractor or Water Users' Association (WUA), or both. In this context modification of design is also made frequently during the construction stage. 
The accuracy of planning and design analyses depends on the accuracy of hydrological, agricultural, geological, topographical, and other data (DoI, 2006) [2]. The surveyor spends in the field to collect data with agreed time and other resources. But in practice, there is no proper and accurate extraction of data to reflect the real site condition which generates a gap between designed structures and real needs in the field. If improperly designed infrastructures are constructed without design review they may not function properly. In the context of Nepal's Department of Irrigation generally constructs irrigation canals under various development programs such as Community Managed Irrigated Agricultural Sector Project (CMIASP AF/Batch-II) is one such program launched by DoI to improve community irrigation systems. Small scale irrigation projects are initiated by the Department of Local Infrastructure Development and Agricultural Roads (DoLIDAR) in recent years. Community Irrigation Project (CIP) and Small Irrigation Programme (SIP) are two projects which are being launched by DoLIDAR. Community Irrigation Project covers twelve mountain, hill, and Terai districts for viz. Mugu, Jumla, Bajhang, Doti, Rukum, Rolpa, Pyuthan, Salyan, Dang, Kapilbastu, Kailali and Kanchanpur. Survey and design work is done by a consultant and implementation work is done by both WUA and contractors. The change in design in structures is generally seen during the construction stage.

\section{PROBLEM STATEMENT :}

Designing is the mother of construction which is why perfection in design is most [3]. This means the design should be converted in construction with the least changes during construction. Dissatisfaction with large scale system performance and a growing awareness of the wealth and extent of indigenous irrigation experience that is typically small scale has prompted governments, donor agencies, and lending institutions involved in irrigation development to review successful small scale experiences in the hope of developing a format to promote the growth of small scale schemes. The extent of use of small-scale irrigation is perhaps much greater than one might expect (Wisney \& Walter, 1985) [4]. It is estimated that around a 0.88 million ha of land (64\% of the total irrigated area) is covered with Farmer Managed Irrigation System in Nepal (Singh et al., 2015) [5].

\section{OBJECTIVES :}

The general objective of the study is to analyze the current status of design reviews in small irrigation projects in the Dang Valley of Nepal.

\section{LITERATURE REVIEW :}

\subsection{Classification of Irrigation System:}

Irrigation systems are classified in two ways: based on management and based on the size of the command area:

Based on management: - Based on management practice, the irrigation systems are classified as: Farmer Managed Irrigation System (FMIS), Joint Managed Irrigation System (JMIS), Agency Assisted Irrigation System (AAIS), and Agency Managed Irrigation System (AMIS).

Based on the size of the command area: - Irrigation systems are classified as major, larger, medium, and small irrigation in Terai and Hill, based on the size of the command area (DoI, 2014) [6].

Table 1: Classification of an irrigation system according to the size of the command area

\begin{tabular}{|l|l|l|}
\hline \multicolumn{1}{|c|}{ Type } & \multicolumn{1}{c|}{ In Hills (Ha.) } & \multicolumn{1}{c|}{ In Terai (Ha.) } \\
\hline Major Irrigation & $>1000$ & $>5000$ \\
\hline Large Irrigation & $(500-1000)$ & $(2000-5000)$ \\
\hline Medium Irrigation & $(10-500)$ & $(100-2000)$ \\
\hline Small Irrigation & $<10$ & $<100$ \\
\hline
\end{tabular}




\subsection{Design Aspects of Irrigation Structures:}

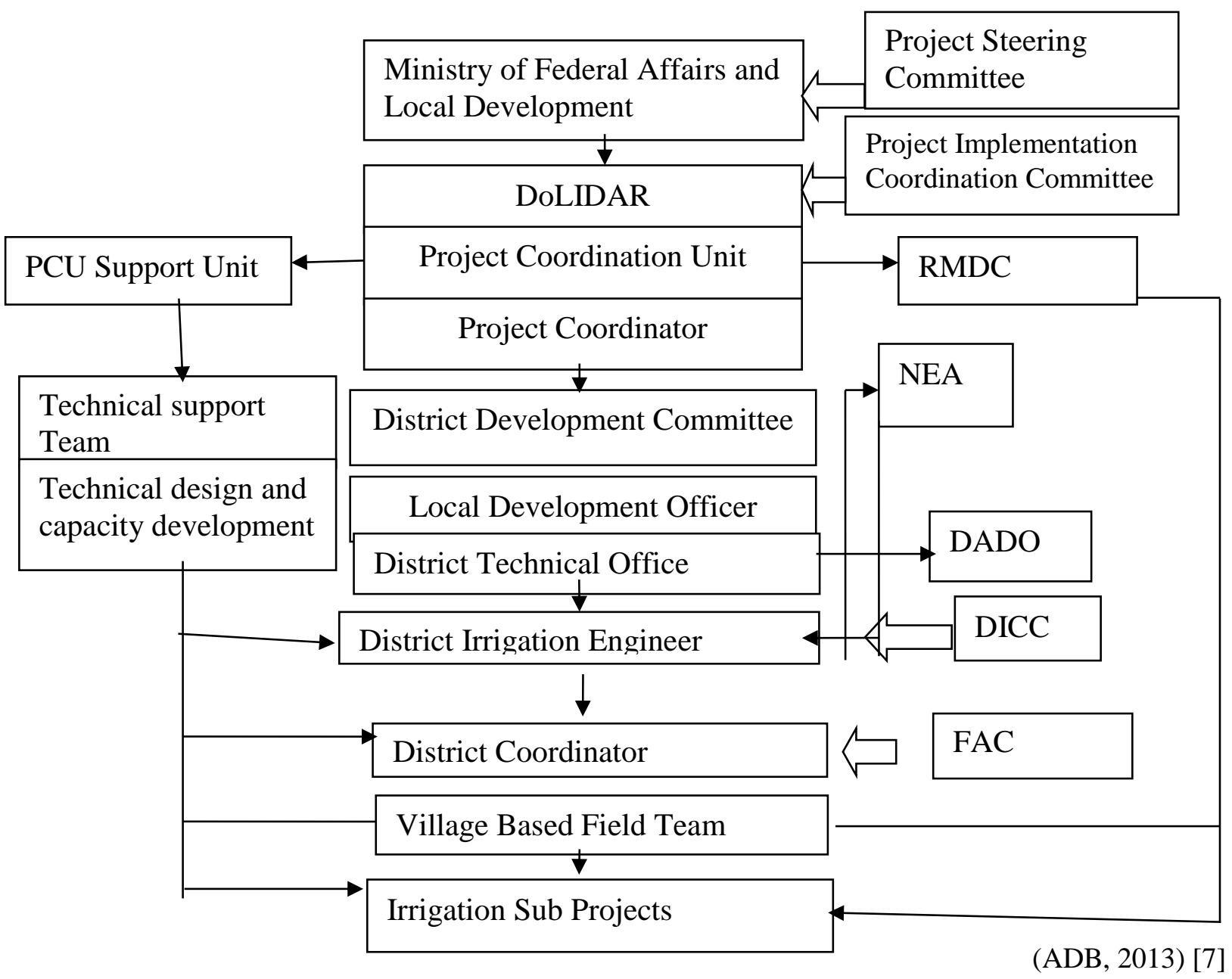

Fig. 1: Project Organization Structure

As per the Feasibility Assessment Report design steps are as follows (DoLIDAR, 2013) [8]:

Estimation of flow at diversion site

Site investigations

Walkthrough survey

Mapping

Agricultural and socioeconomic data collection

Environmental screening

Detail design

Review and approval of the design by DoLIDAR

Implementation

Completion of work and hand over to WUA

There is the provision of a cost ceiling during the project design. $\$ 1000$ per hectare for rehabilitation of schemes and \$1500per hectare for new construction of the system is one of the criteria for the project selection. This criterion limits the design for the complete system. Due to this many schemes are later completed with a variation. The head of the executing agency for the Community Irrigation Project (CIP) is the Ministry of Local Development. The Department of Local Infrastructure Development and Agricultural Road (DoLIDAR) handles all the sub-project's approval and implementation. District level team of various stakeholders such as the District Development Committee, District Technical Office is responsible for screening selection, and implementation of subprojects. Consultant and NGO team support the district team to carry out each activity. 
Irrigation design involves more than the technical design of irrigation structures. Wider aspects of irrigation schemes such as Scheme objectives, Agricultural consideration, Managerial and institutional arrangements, Social arrangements, financial arrangements, and Engineering solutions.

Need to be taken into account and reflected in the design of an irrigation system (Jacob, 1995) [9]. It indicates that irrigation design is not only focused on technical design only but depends on the abovementioned various factors that need to be assessed during the design process.

The design process in irrigation development has traditionally been the domain of civil engineers. Hydraulic and physical design principles are applied in getting water from a supply source to the root zone of plants (Yoder, 1994) [10]. As per him, obvious information essential for carrying out the design process includes the crop water requirement, expected moisture contribution from rainfall, losses by evaporation and seepage, high flood level value, etc. The information such as water rights among systems, water allocation, and rules for operation and maintenance are frequently neglected.

Most of the hill irrigation projects constructed in Nepal are conventional surface irrigation systems based on a run of the river system. Hill and mountain conditions particularly present severe challenges to the irrigator (DoI, 2006) [6]. As per DoI (2006) [6], problems of landslides, canal leakages, shifting of rivers, long canals for small irrigable areas are common. The major issues can be stated as:

- Fragile mountains causing instability

- Sediment and violent behavior of rivers

- Flow variations

- Choice of intake

- Seepage losses

- Labor scarcity

- Lack of uniform design approach

- Inadequate design of irrigation system

The document indicates that these variable factors affect the design of irrigation canals. Design in this context refers to the dimensioning and specification of engineering works rather than the design of agricultural plans or institutional arrangements. At the detailed design stage, layout plans would be finalized, and channel and structure dimensions and details would be confirmed to a sufficient standard for contractors to price with fair accuracy. For most irrigation projects, some design work may have to be done on-site during construction. In general this will:

- Provide contractors with the exact levels and dimensions of individual minor structures.

- Confirm design levels and dimensions of major structures.

- Confirm locations, levels, and dimensions of canals/drains.

- Take account of changes in circumstances, and correct for these.

- Take account of errors or discrepancies in original survey data.

- Allow for extras to or omissions from the detailed design.

(PDSP, 1990) [11]. The manual focuses on the Hydraulic considerations like Levels, Capacity, and Sizes of the canal, Safety, and Distribution along with Structural considerations like Foundations, Strength, and Materials as crucial for the design of irrigation canals.

The plan of water system frameworks should be suitable and adaptable to reflect neighborhood needs and conditions. The undertaking configuration stage gives the chance to distinguish possible issues and suitable arrangements in light of a bunch of options. The thought of choices was significant in the possible achievement of undertakings in Bangladesh, the Republic of Korea, and Pakistan. A suitable plan should be founded on neighborhood conditions and experience. Adaptability in planning tasks to reflect neighborhood conditions and stay away from negative ecological effects is likewise great practice. For example, the Nepal and Philippine encounters of reinforcing water client/rancher establishments can be imitated in regions where little water system frameworks are vital. In Bangladesh and Pakistan, the consolidation of illustrations in the plan of tasks that have an effective point of reference are instances of good practice that added to inevitable venture achievement (ADB, 2008) [12].

\subsection{Aspects of Design Challenges:}

Design is one of the most important parts to be performed before implementation. If the proper survey is done, the design can be accurately performed. However, if there is a lack of experienced and competitive designers then the design may not be good despite good surveys. Participatory process in the development and management of public sector irrigation came as a new strategy, aiming at the 
solution to ever-increasing constraints on the government to improve the performance of the irrigation sector to achieve the full potential of public sector irrigation schemes (Sharma \& Shukla, 1997) [13]. The failure of many irrigation structures is not due to incorrect hydraulic or structural design but because they cannot be operated or maintained at certain times. Often, it is difficult to identify the adverse conditions during the design period. So, there is a need for interaction with farmers and designers to have an effective design (Yoder, 1994) [10].

Even rehabilitation is not necessarily valued in the same manner by all users. The problem of canal siltation is illustrated by agency staff as an unsatisfactory facility whereas the farmer near the head thinks that is an opportunity for him to take sufficient volume. If the canal is cleaned then depth decreases due to the elimination of vegetation and silts providing shallow depth for head users. So these type of problems needs to be considered while designing (Abernethy, 2015) [14]. Given the importance and large investment required, the efficiency and effectiveness of water delivery and use are of primary concern. In general irrigation activities undertaken in Nepal to date have not been very successful. Many projects have not reached their planned levels of productivity and many are not financially or technically sustainable in their present form. The most appropriate forms of irrigation have not always been used and many technologies and techniques available around the world for the efficient application of water are not now commonly used in Nepal (DoI, 2006) [6].

For the packaging of work, WUA should involve in the tail part and the contractor should involve in the head part of the canal so that delay in work by WUA should not affect the contractor's work.

The need to carry out participatory design is not only self-evident in that the water users are not only the beneficiaries but also those that understand their irrigation system best: where canals and structures are damaged, constraints to operation, and have their views on how the system could be improved (ADB, 2008) [12].

Modernization is investing in depth by applying modern management techniques to improve irrigation efficiency of irrigation systems, along with changing perceptions about water use and management, regarding water as a kind of commodity and irrigation as a type of service in agriculture production. Investments in existing irrigation systems are not complicated in terms of techniques, not big funding requirements (compared to new construction) but can be able to obtain high stability and sustainability. The "Bottom-up" approach is probably of the utmost importance. A true basic needs policy implies the need for a bottom-up approach in planning so that in each region optimal packages including carefully designed networks in rural areas can be offered to achieve the objectives (UN, 1979) [15].

To meet adequately the project management needs of CIP, a project management methodology has been developed by the project team. A flow chart of the project management methodology of CIP is shown in figure 2 .

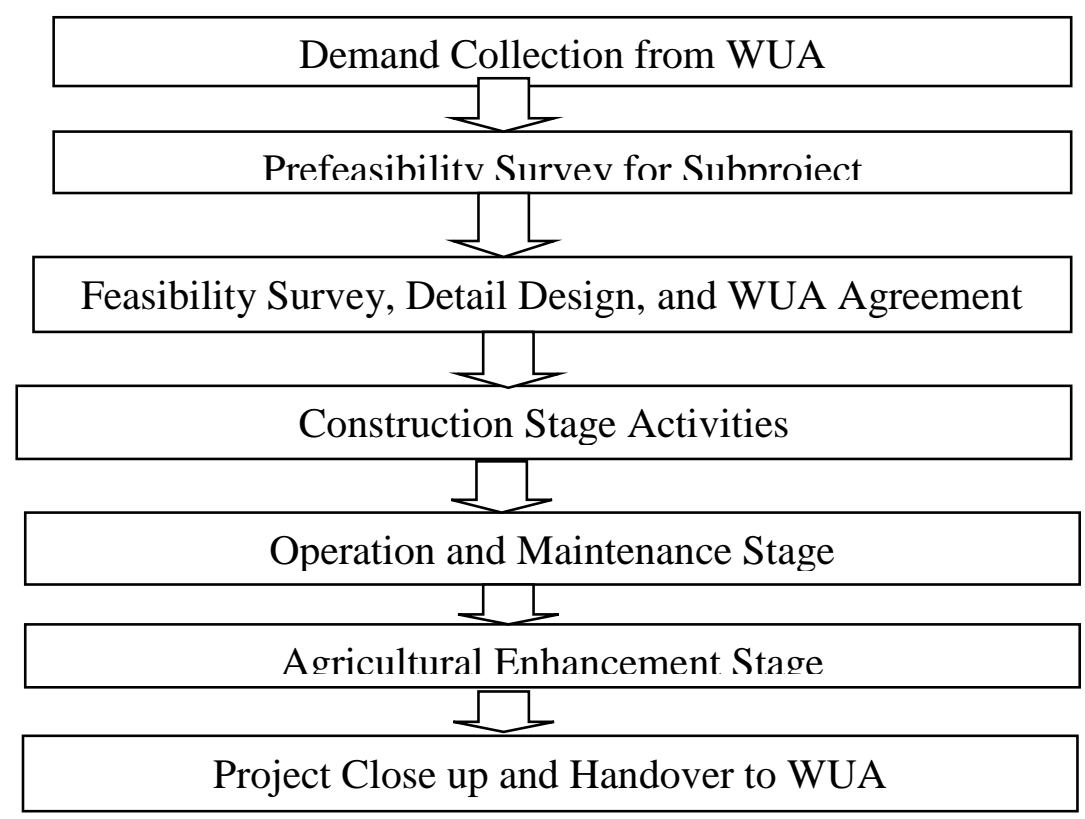

Fig. 2: Project Management Methodology of CIP 


\section{METHODOLOGY :}

\subsection{Research Design Flow Chart:}

The problem was identified and defined for the establishment of the objective of the study than the development of a research plan. Literature Review and supervisor guidance was continued throughout the research period. In this study, data were collected by using the questionnaire survey method. Nine numbers of key informant interviews and site observations were also conducted to extract primary data in the field. Similarly, secondary data was collected through reports, documents of projects, previous research, etc. After collecting the data, it was analyzed using statistical tools and illustration methods. A cause and effect diagram was also used to elaborate design change causes and effects. After the analysis of data and discussion, the findings of the studies were concluded by providing recommendations for the raised issues. Problem identification related to the selected topics of research, setting of the objectives, and design of questionnaire for respondents (general respondents and project stakeholders) were developed in the pre- fieldwork phase.

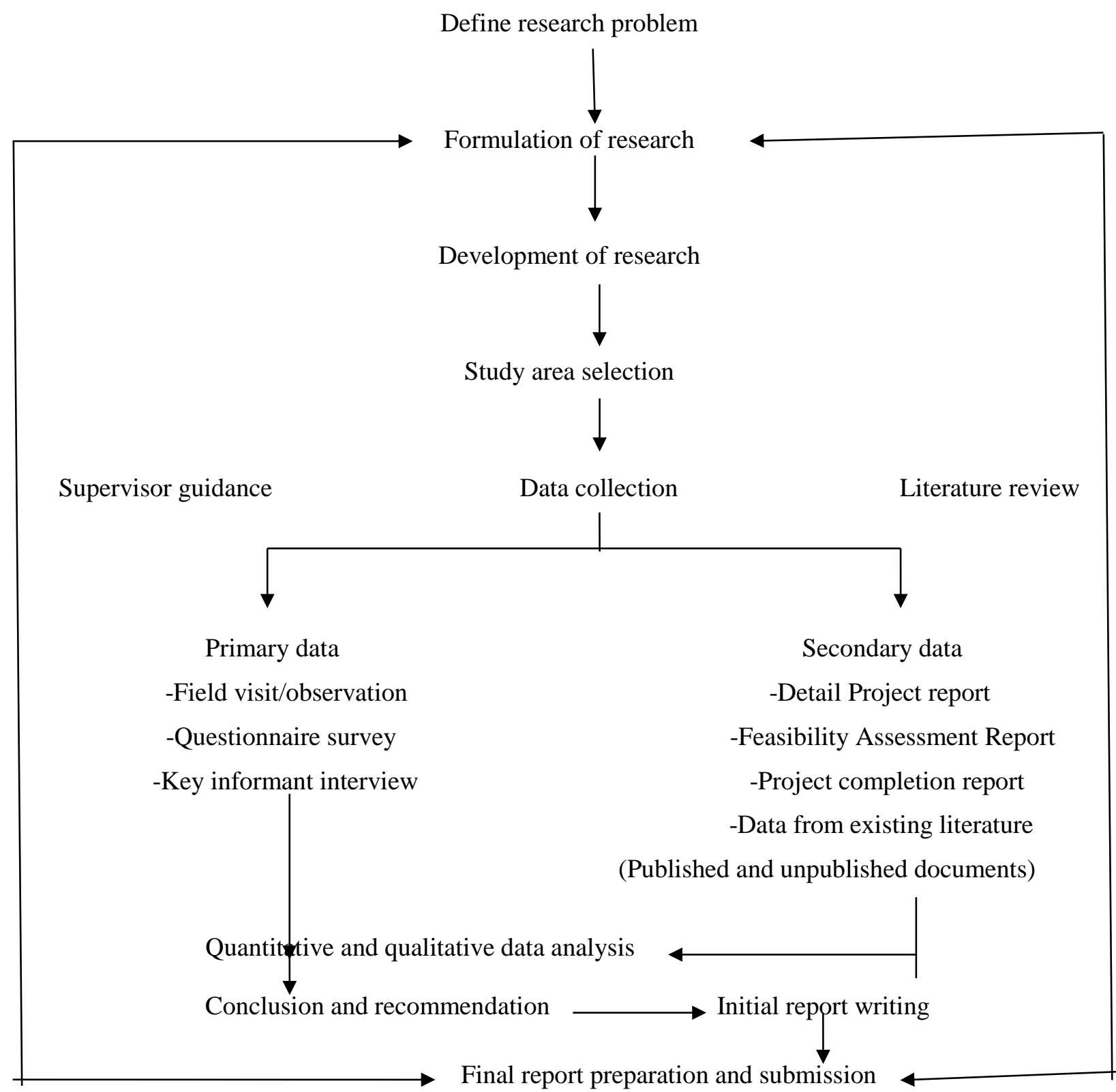

Fig. 3: Research Design Flow chart 
Fieldwork Phase:

Observation of field, conduction of questionnaire survey, and collection of primary data related to the small irrigation schemes were done in the field. Similarly, the secondary data were collected from detailed project reports, project completion reports, and as-built drawings. Primary data was collected by conducting a questionnaire survey with stakeholders such as clients, consultants, contractors, and WUA/farmers in the field.

\section{Post Fieldwork Phase:}

In the post fieldwork phase, processing and analysis of data, to illustrate the result regarding the subject matter, drawing of conclusion and making a necessary recommendation and final report preparation was done.

\section{Research Approach:}

In this thesis, a qualitative approach was used to find the factors causing variation in design during the construction phase, and a quantitative approach was used to test the significance of design review impact of small-scale irrigation schemes.

\subsection{Study Area:}

Small surface irrigation schemes of Dang valley conducted by the Community Irrigation Project (CIP) were selected for the study because it is situated in the transitional area between Hill and Terai. It contains fifteen schemes that are under the implementation stage. As Dang is the biggest and most fertile valley in Nepal, improvement in a small-scale irrigation system can significantly support the cost-effective design and implementation for the increase of cropping intensity and crop yield. For this, an effective irrigation system is essential with the involvement of beneficiary farmers.

\subsection{Sample Size and Selection:}

In this study, population means all the small surface irrigation schemes of Dang valley conducted by CIP. The population is fifteen surface irrigation schemes located in Dang Valley. Since the population was small in number $(\mathrm{N}=15)$ so all small surface irrigation sub-projects conducted by CIP were taken into consideration. Three ISPs were taken as case studies by area sampling method to cover different locations in the valley.

The response rate for the questionnaire survey is shown in table no.2.

Table 2: Total samples used for research

\begin{tabular}{|l|l|l|l|l|l|}
\hline $\begin{array}{l}\text { S. } \\
\text { N. }\end{array}$ & $\begin{array}{l}\text { Targeted } \\
\text { Respondents }\end{array}$ & Population $(\mathbf{N})$ & Sent & Received & $\begin{array}{l}\text { Rate of Return } \\
(\%)\end{array}$ \\
\hline 1 & Client staff & 8 & 8 & 7 & 88 \\
\hline 2 & Consultants & 11 & 11 & 10 & 91 \\
\hline 3 & Contractors & 5 & 5 & 5 & 100 \\
\hline 4 & WUA & 15 & 15 & 14 & 93 \\
\hline
\end{tabular}

The parties related to the project such as the Client, Consultant, Contractors, and WUA were subjected to participate in the questionnaire survey, and farmers were also interviewed on the subject.
i. $\quad$ Client
ii. Consultant
iii. Contractors
iv. WUAs

For the research purpose, small-scale irrigation schemes in Dang valley were analyzed for the study of design variation and its causes along with remedial measures to narrow the gap between the design and construction stage.

\subsection{Collection of Data:} Field visit/observation

The field visit was done to each case study structure to find out the changes in design during the construction phase. The observation supported knowing the causes of design change and its necessity. 
Questionnaire Survey

After the validity of the questionnaire, the questionnaires were distributed to the respondents of clients, consultants, contractors, and WUA representatives. Ninety percent of the questionnaire were distributed by visiting them on-site while ten percent of the questionnaires were sent by email. Most of the respondents have positive responses regarding the questionnaire. On average $92 \%$ response rate was achieved which was very high and was possible due to continuous field visits to the site.

\subsection{Analysis of Data:}

Collection of project reports and Questionnaire survey made the researcher assess the operational status of the Design Review which is illustrated through bar chart, pie chart, table to assure logical valid response to the situation of design Review.

\section{RESULTS AND DISCUSSION :}

\subsection{The Design Review Practice:}

The various aspects such as project selection methodology, detail survey, design, and design review practices were asked to a representative of the client, consultant, and contractors for small farmermanaged irrigation schemes and analyzed with the help of an excel sheet.

\subsubsection{The Project Screening and Selection Practice:}

The representative of the client, consultant, and contractor were interviewed by administering a questionnaire for the project selection practice of small irrigation schemes. Table 3 shows the approach of project selection and screening practice.

Table 3: Project Screening and Selection Practice

\begin{tabular}{|l|l|l|l|l|l|}
\hline Approach & Client (\%) & Consultant (\%) & Contractor (\%) & WUA (\%) & Overall (\%) \\
\hline Bottom-up & 100 & 100 & 20 & 71 & 78 \\
\hline Top-down & - & - & - & & - \\
\hline $\begin{array}{l}\text { Political } \\
\text { pressure }\end{array}$ & - & - & - & 15 & 6 \\
\hline Don't know & - & - & 80 & 14 & 16 \\
\hline
\end{tabular}

Table3 shows that the bottom-up approach was most frequently used to select the project during the screening period. It encourages participating the beneficiaries to address their problem effectively. This process reduces the potential conflict among the stakeholders and facilitates the project to complete on time. The figure indicates that clients and consultants are claiming that they are involving farmers for project selection but only $71 \%$ view from WUA representatives agree that the process is from a bottomup approach.14\% of WUA still believe that schemes are selected from political pressure too. So there is still room available to improve the process by selecting fully from this approach.

\subsubsection{Farmers' Participation in Project Selection Process:}

Farmers' participation in the project selection process plays a pivotal role for to fulfill the actual demand in the field. If farmers are fully engaged to select the project real need can be addressed for better production in the field. If projects are selected directly by the Government of Nepal or donor agencies then it can create a problem for sustainability. In CIP most projects are selected with the full involvement of farmers that can be observed by the perception of respondents from Table 4 and Figure 4-1.

Table 4 : Farmers' participation in Project Selection Practice

The Farmer's Participation in Selection Process

\begin{tabular}{|c|c|c|c|c|c|c|c|c|c|}
\hline a. Fully & $\%$ & b. Partly & $\%$ & $\begin{array}{l}\text { c. selected } \\
\text { by } \\
\text { donor/GoN }\end{array}$ & $\%$ & $\begin{array}{l}\text { d. Don't } \\
\text { know }\end{array}$ & $\%$ & Total & $\%$ \\
\hline 23 & 64 & 8 & 22 & 2 & 6 & 3 & 8 & 36 & 100 \\
\hline
\end{tabular}




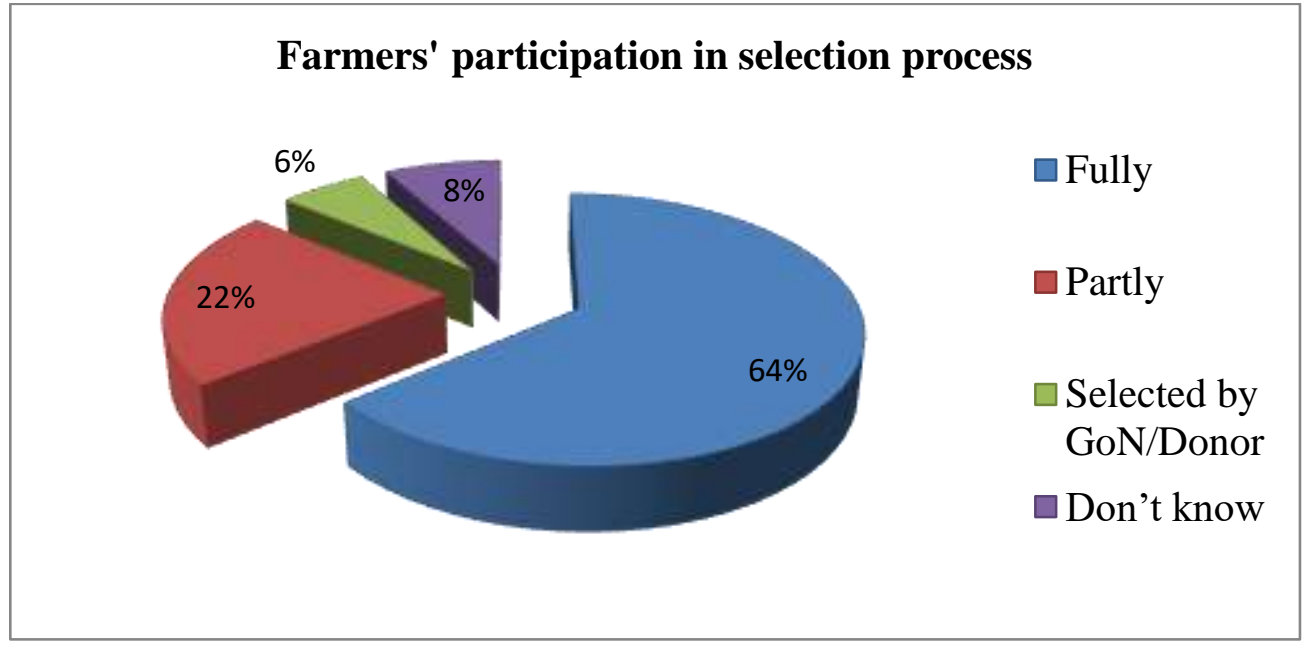

(Field data analysis, 2021)

Fig. 4: Farmers' participation in the project selection process

Figure 4 reflects that farmers' participation in the project selection process is at a satisfactory level wherein $64 \%$ of respondents have reported that they had been practicing to select the project fully whereas $22 \%$ said that they had been involved partly selecting the project. Sharma \&Shukla (1997) [13] state that participation in irrigation aims at shifting primary management responsibility to the water users with contraction of the government's role and a corresponding increase in the role of the water users. So, participation of farmers in the project selection process should be fully incorporated to lessen the design review activities. Figure 4 indicates that there is still sufficient room to participate farmers fully to involve them in the project selection process.

\subsubsection{The Detail Survey and Design Practice:}

Detail survey and design work is the most important activity for the cost-effectiveness and sustainability of the system. The result of the questionnaire survey related to the detailed survey and design work has been presented in table 5 .

Table 5: Participation of beneficiaries in detailed survey work

\begin{tabular}{|l|l|l|l|l|l|}
\hline Description & Client (\%) & Consultant (\%) Contractor (\%) & $\begin{array}{l}\text { WUA representative Overall (\%) } \\
(\boldsymbol{\%})\end{array}$ \\
\hline Yes & 100 & 100 & 100 & 86 & 94 \\
\hline No & 0 & 0 & 0 & 14 & 6 \\
\hline
\end{tabular}

(Field survey, 2021)

Table 5 shows that beneficiaries have been highly participating in survey work which is a very strong point for the sustainability of farmer-managed irrigation schemes. More information related to topography, hydrology, geology, and social issues can be known before design. Participatory survey work can be more beneficial for cost-effective and sustainable design. As per PDSP (1990) [11], proper surveying is needed to enable accurate design for schemes. Participation of beneficiaries ensures proper demand and management of materials for proper design. Yoder (1994) [10] also stressed participation and interaction with farmers during survey time to have an accurate design.

\subsubsection{The Financial Aspects of Design Practice:}

Financial aspects directly influence the design aspects because more budget is needed if more demand is to be fulfilled as per field site conditions. However, if there is a budget constraint then it seems hard 
to address all the demands from the community. As per the nature of the project funded by ADB, it was found that there is a budget ceiling in the project which was also verified by the administering questionnaire to clients, consultants, contractors, and WUA representatives that there is a budget ceiling in the project. The result of the questionnaire survey related to the influence of budgetary constraints for schemes has been presented in Table 6 .

Table 6: Condition of the budget ceiling in the project

\begin{tabular}{|l|l|l|l|l|l|l|l|l|}
\hline Yes & $\%$ & & No & $\%$ & Total & $\%$ \\
\hline 32 & 88.89 & 4 & 11.11 & 36 & 100 \\
\hline
\end{tabular}

(Field survey analysis, 2021)

Table 7 indicates that there is the provision of the ceiling of the budget during the design of the project. Chief District Engineer during key informant interview said that there is the provision of $\$ 1000 /$ ha for rehabilitation of projects and $\$ 1500 /$ ha for construction of new projects which is the main cause to review the design for optimum utilization of resources to address farmers' issue. Yoder (1994) [10] stressed that low-cost design is effective when there is a contribution from WUA, a budget ceiling for structures and an effective accounting system exists.

From the Survey, $89 \%$ of respondents argue that budget ceiling influences the design process negatively. It creates a barrier to designing the system fully from the head to the tail area. So, it finally invites an incomplete design which compels for the design review process.

\subsubsection{Overall Design Review and Approval Practice:}

Design review and approval process refine the design to fulfill the demand with actual site condition considering available resources. So, it optimizes the design with cost and quality.

The overall design review and approval practice. $72 \%$ of respondents said that there is the practice of overall design review and approval practice whereas $28 \%$ deny the issue. Clients, consultants, contractors, and WUA representatives agreed that the overall design review and approval system optimizes the design in terms of optimization of resources and their utilization which is most important in the context of limited resources.

\subsubsection{Sufficiency of Design for Implementation:}

Design should be sufficient and complete for implementation. If the design is incomplete and not addressed properly with the site conditions it is hard to implement it during construction. Different stakeholders have different versions regarding the completeness of the design.

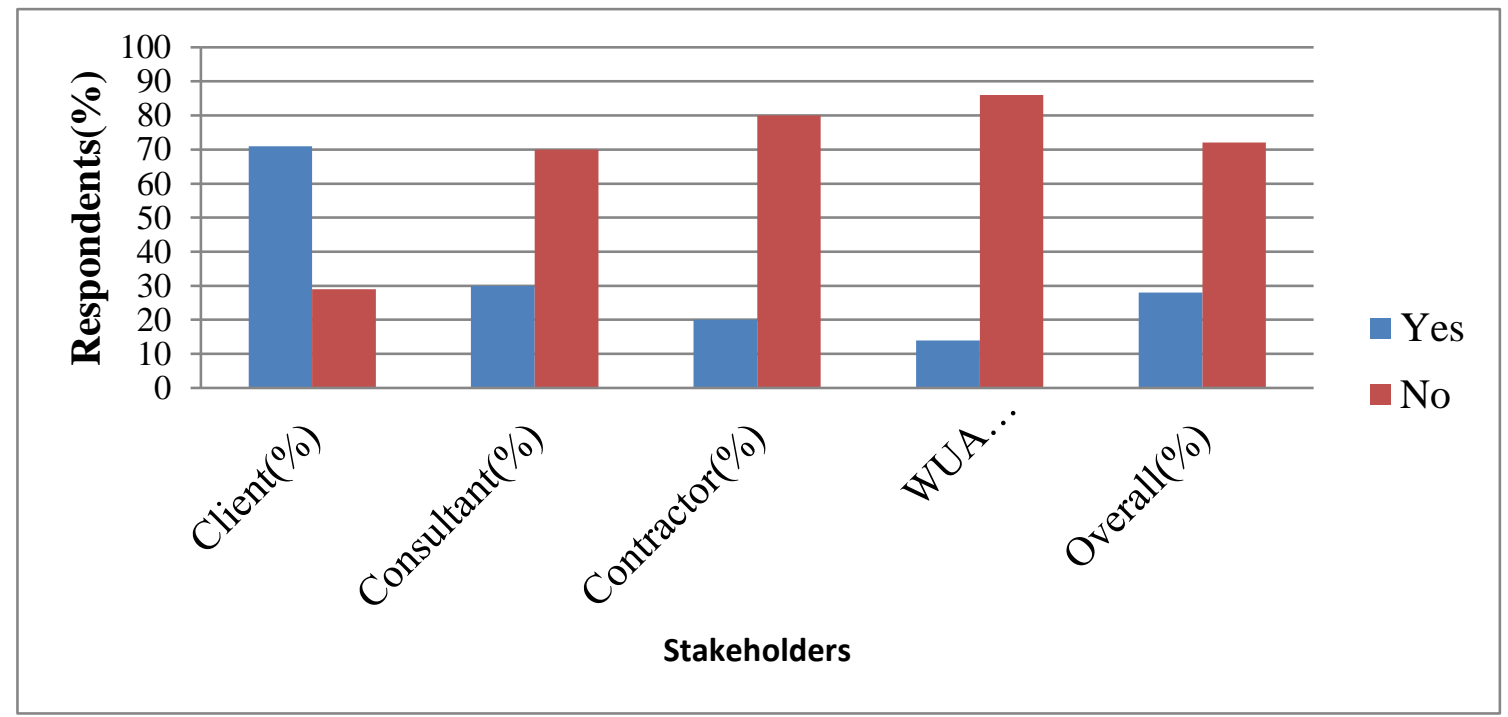

(Field survey analysis, 2021)

Fig. 5: Sufficiency of design for implementation 
Figure 5 shows that $71 \%$ of clients said that design is sufficient for implementation however most of the contractor's consultants and WUA representatives are against this version. They said that design is not sufficient for implementation without correction and review. Overall, $72 \%$ of respondents say that the current practice of design is not sufficient for direct implementation. Only $28 \%$ of respondents believe that the current design practice is sufficient for implementation. This discrepancy between the client and other stakeholders can be seen clearly from the graph. This is because of the overconfidence of the client for the implementation of the project.

\subsubsection{Design compatibility:}

Design is one of the critical steps in the project cycle. If the design is not compatible with users it creates a problem for the completion and operation stage too. The respondents opined in this matter in different ways related to CIP projects in Dang Valley.

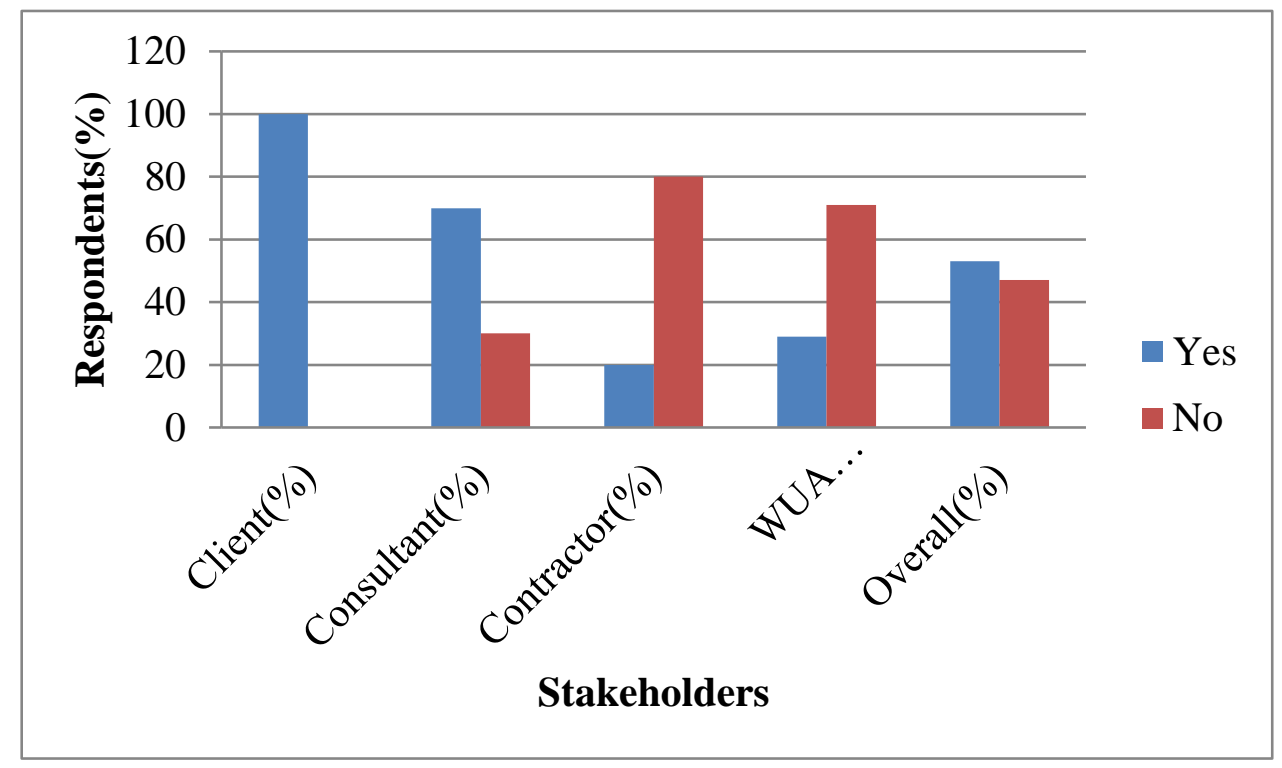

(Field survey analysis, 2021)

Fig. 6: Compatibility of design with demand

Figure 6 describes the compatibility of design with demand.100\% of client respondents and $70 \%$ of consultant respondents say that the design is compatible with the demand. However, $80 \%$ of the contractor and $71 \%$ of WUA respondents deny this. They say that the design is not compatible with demand. Overall, $53 \%$ of respondents agree on compatibility and $47 \%$ deny this. This contradiction between designer and implementer is seen clearly in the figure. This gap is due to less communication during the stage of survey and design with respective stakeholders. Another reason for the gap is due to lack of sufficient resources to address the unlimited demands. This indicates the need for design review to fulfill the gap. Adhikari \& Basnet (2007) [16] stressed that the benefit of irrigation rehabilitation could be of many folds if the design fits physical and socio-technical settings.

\subsubsection{Consideration of social and environmental issues in design:}

Environmental and social issues are becoming more important nowadays while designing the project. The effect of project implementation on the environment may occur at different intensities and levels which can be expressed in terms of magnitude, space, and time. If not addressed properly these issues delay the completion of the project. The response from the stakeholders related to consideration of environmental and social issues in design have been presented in Figure 7. 


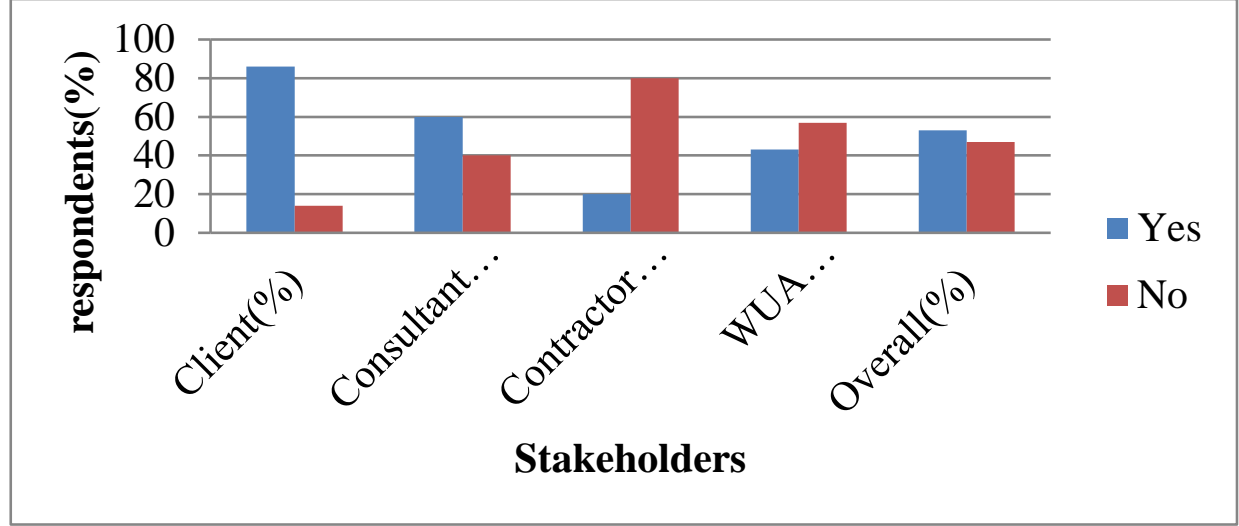

Fig. 7 : Consideration of environmental and social issues in design

(Field survey analysis,2021)

Figure 7 shows that the client and consultant agree that they have included environmental and social issues properly in the design while contractors and WUA argue that these factors are not properly addressed in the design. Overall $53 \%$ of respondents say that these issues are properly addressed while $47 \%$ believe that these parameters are not properly addressed. This also shows that there is a need for design review to resolve the problem to smoothly conduct the construction activities.

\subsubsection{Status of implementation as per design:}

Implementation of works in the field concerning design is the most important part during the project cycle because if any improper construction work is done can only be corrected by extra cost and time. In this context, stakeholders responded in different ways which have been shown in Figure 8.

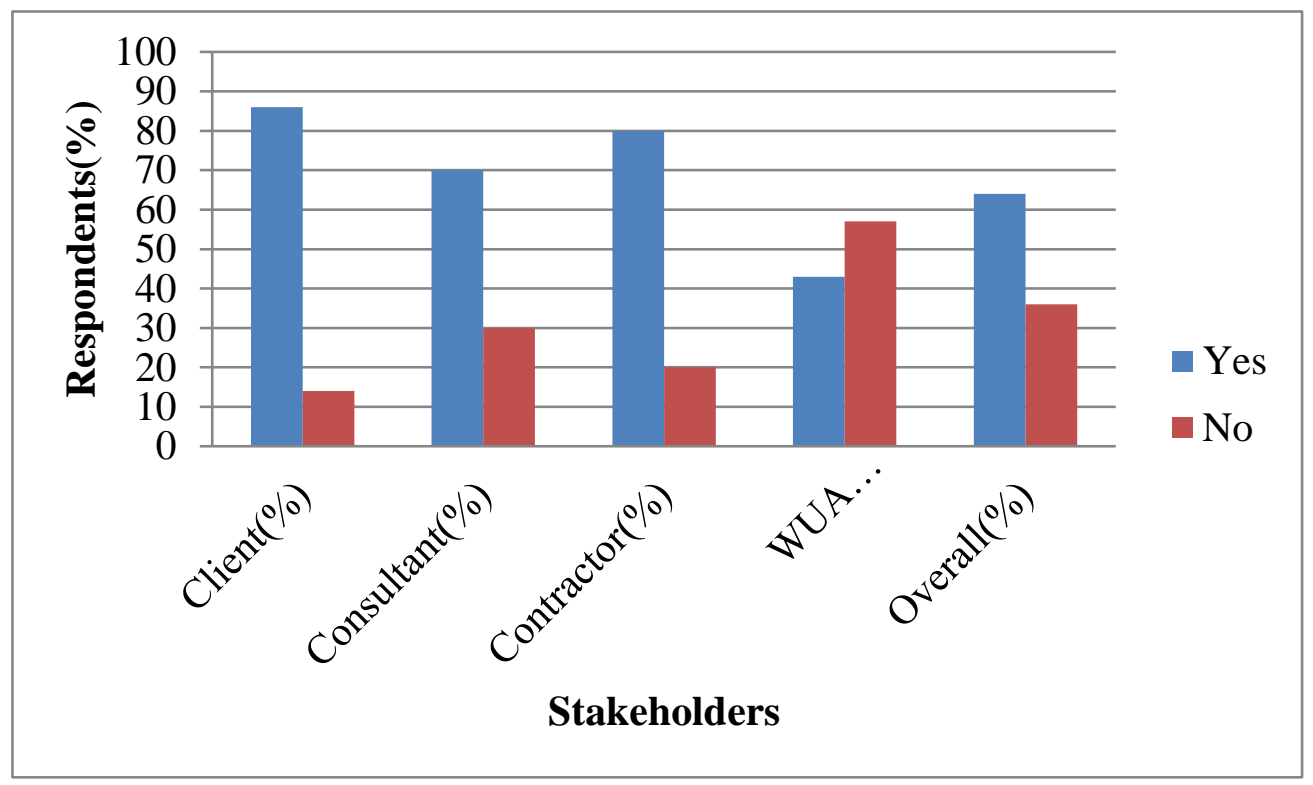

Fig. 8: Status of implementation of work concerning design

(Field survey analysis, 2021)

Figure 8 shows that clients, consultants, and contractors believe that implementation of project work follows design while the majority of WUA representatives think that implementation of fieldwork occurs without the following design. This gap needs to be addressed by regular communication with WUA representatives. 


\subsubsection{Information of Design:}

In the participatory approach of planning and design, there is a need of informing each activity's beneficiaries. Design and its review is a critical process of the project cycle so there is a need for information dissemination to WUA so that the system becomes cost-effective and farmer-friendly in nature. Most of the respondents agree that design is informed to WUA which is a very vital part of the participatory approach for the construction of irrigation schemes. This reduces the chance of a communication gap between the implementer and beneficiaries.

Clients, consultants, contractors, and WUA are the key stakeholders throughout the project cycle. If most of the parties are involved during the design review, it supports understanding easily the nature of work and facilitates further implementation stage. If only either client or consultant is involved it takes time to further clarify the matter before implementation. The respondents from various stakeholders were asked whether they were involved in the design review process or not. The involvement from client and consultants were found to be more dominant than other implementer stakeholders.

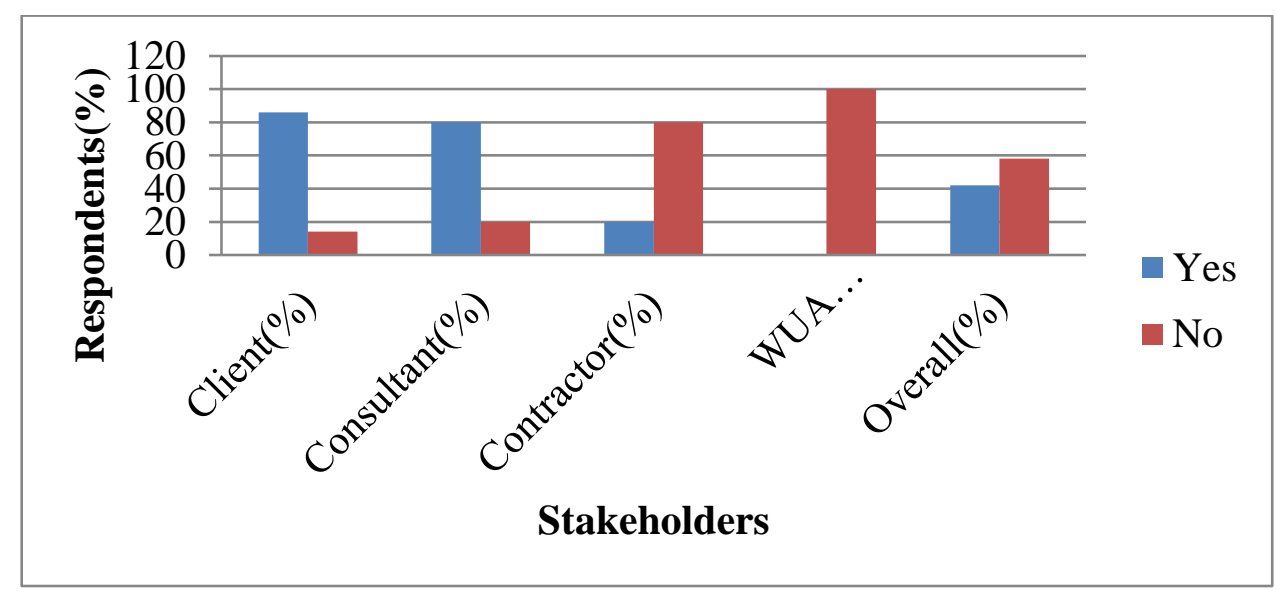

Fig. 9: Involvement of stakeholders in design review

(Field survey analysis, 2021)

Figure 9 shows that most of the clients and consultants were involved in the design review process while most of the contractors and WUA representatives were not involved in the design review process. This is the prevailing practice in the context of Nepal.

\subsubsection{Consideration of Use of Local Materials in Design:}

Local material utilization not only strengthens sustainability but also makes the design cost-effective. This occurs because the use of local materials facilitates WUA for easy operation and maintenance. These materials are cheap and easily available which supports maintaining the system with minimum time.

Overall $92 \%$ of respondents believe that local materials are prioritized during the design while only $8 \%$ deny this. Utilization of local material supports design cost-effectively and sustainably. If properly managed this reduces the design review work. As per Yoder (1994) [10], frequent modification of design takes place if local materials are neglected.

\subsubsection{Status of Design Review in Small Irrigation Projects:}

Design review practice supports for optimum utilization of resources shows that the majority of clients believe that more than $50 \%$ of projects undergo design review while the majority of consultants believe that $<50 \%$ of projects undergo design review. Similarly, the majority of WUA representatives believe that $<50 \%$ of irrigation projects undergo design review. Overall most of the respondents agree that $<50 \%$ of small irrigation projects undergo design review. As design review supports the sustainability of the system with optimum utilization of resources there is a need of increasing the design review process for small irrigation projects. 


\subsubsection{Time Needed for Design Review of a Small Irrigation Project:}

Time is always an important factor to complete the project because as the time is the extended extra cost is needed for completion along with the delay of project installation and operation. For small irrigation projects, design review for an effective and sustainable system is essential but the time needed for review is also important. The respondents believed that around one to one and a half week is sufficient to review for a small irrigation project located in Dang Valley. The overall $50 \%$ of respondents believe that 5-10 days is sufficient for a design review of a small irrigation project. Similarly, only $30 \%$ believe that $10-15$ days is needed for design review while only $12 \%$ say that it needs less than 5 days and 8\% say that it takes 15-30 days. None of them believe that it takes more than 30 days. It indicates that the time taken for a small irrigation project for its review does not contribute significantly to the delay in the completion of the project.

\subsubsection{Nature of Redesign Process in Irrigation Projects:}

The redesign is done in various ways. Sometimes redesign is done to improve quality, to change the type of irrigation schemes (e.g. earthen system to canal system or pipe system), redesign for location change. Location is usually changed when the surveyed location changes because of changes in river morphology, improper selection of location, etc. It was asked for the respondents to find the nature of redesign who were representing clients, consultants, contractors, and WUA and mainly involved in the design process. Overall $54 \%$ of respondents say that there is a change in location in the redesign process. Similarly, $33 \%$ believe that there is a re-estimate for quantity. Only $8 \%$ believe that it is done for quality and $5 \%$ believe that it is done for change in type. It indicates that there is a lack of proper survey and change in demand of beneficiaries during implementation.

\subsection{Design Review Practice:}

\subsubsection{Sufficiency of Design Review Practice:}

As the design is a critical step in the project cycle, it needs reiterative activity to optimize for cost and quality. Generally, the consultant is most responsible for the design. If improperly designed significantly affects negatively the project despite competency for the selection to design. Further, the topographical and sediment condition of the river intake site and other locations might have been changed because of the changing condition of rainfall, floods, and sediment flow. For this review of design before implementation is essential to fit with the real site condition just before construction. The respondents argued that the present design review practice is not sufficient to address all the technical, hydrological, socio-economical, and other issues. All the stakeholders think that the current design review practice is not sufficient. Overall, $83 \%$ of respondents believe that the current practice of design review is not sufficient while $17 \%$ deny this.

\subsubsection{Current Practice of Design Review:}

Design review can be done by various stakeholders. Clients themselves can review the design after submission by a consultant which is frequent in our context. Consultants also can review the design. Peer review of design can be done by an independent body. Despite its need practice of design review is very preliminary in nature and is done by the client. The client is the major party for design review practice. Overall, $75 \%$ say that client is responsible for the design review process while $16 \%$ of respondents believe that the consultant is responsible. As per the key informant interview with CDE, it was clear that most of the design review work in CIP Dang Valley was done by the client.

\subsubsection{Stage of Design Review Process:}

Design review can be done in various stages of the project cycle. It can be done just after completion of design, after agreement with the concerned implementing body, or during the construction phase. However, as per Jarrett $(2000)[17,18,19]$ design review is very useful before the construction phase because it saves extra cost which would have been expensed to correct after construction and also enhances quality. most of the respondents agree that the design review process should be done after the submission of the design by the consultant. Overall, $83 \%$ believed that it is appropriate after submission of design while only $17 \%$ believe that it should be done during construction. The result indicates that the appropriate stage of design review is just after the submission of the design. As per an interview 
with CIP Engineer Laxmi Sainju, 60\% ISPs were reviewed just after submission while others were reviewed during the construction phase too.

\subsubsection{Farmers' Participation in Irrigation Project:}

Farmer's participation in all planning, design, implementation and management stages of the irrigation project cycle is very important because it not only facilitates easy and farmer-friendly construction but also enhances inclusive participation from every facet of society. It facilitates taking ownership from the WUA side and also supports easy operation and maintenance providing full-fledged information in the pre-construction phase, construction phase, and post-construction phase of the project. In the preconstruction phase, farmers' participation supported to extract of actual field condition which facilitated to design and review the design in a proper way. In the construction phase, farmers' participation ensured ownership feeling and construction mechanism with available local materials. In the postconstruction phase, farmers' participation helped to operate and maintain the canal independently knowing the function of each structure. All the stakeholders agreed that farmers' participation in the full cycle of project development helps in each step of project works. Sharma \& Shukla (1997) [13] also stressed that a participatory approach to planning and design enhances the performance of public irrigation projects despite various constraints.

\subsubsection{Role of Design Review in Construction Phase:}

The design review process helps during the construction phase. If proper design review is done then ambiguities in design and drawing are cleared which helps to enhance the progress of construction activities.

The construction phase is the major time to initiate each activity in the field. For this issue design review seems supportive to clients, consultants, contractors, and WUA in the field. $100 \%$ of respondents from stakeholders agreed that there is a very positive role of design review to work in the construction phase. This necessitates a proper design review system before implementation in the field to optimize the cost for each stakeholder.

\subsubsection{Maintaining Schedule in Construction Stage}

The construction phase is effective if its schedule is maintained. If not maintained, the delay creates cost overrun as well as time overrun. It is very hard to maintain the schedule in the context of Nepal because of various factors such as strikes, unavailability of construction material, and weak resource management by concerned stakeholders. The majority of respondents believed that the construction schedule has not been maintained.

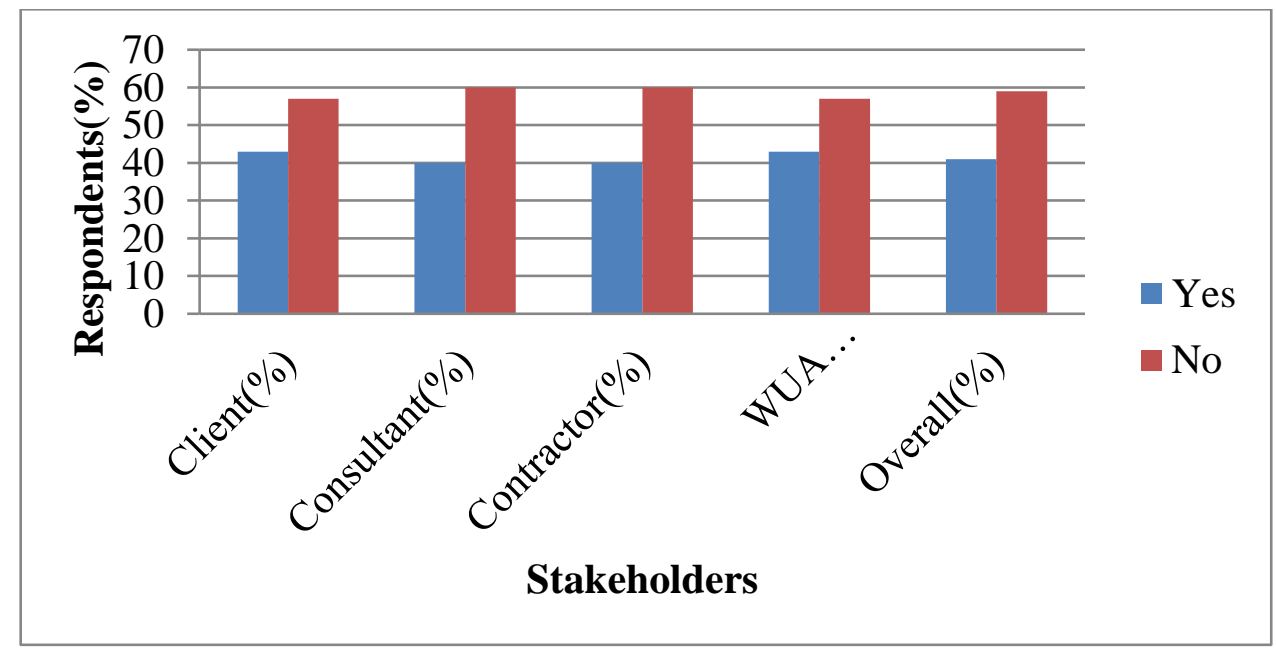

Fig. 10: Status of maintaining the construction schedule

(Field survey analysis, 2021) 
Figure 10 shows that the majority of all the stakeholders agree that there is a delay in construction. Overall 59\% believe that there is a delay in construction work while only $41 \%$ believe that their construction schedule has been maintained.

\subsubsection{Causes of Delay in Construction Stage:}

Delay is an undesired condition in the project cycle however it is frequently faced in our context. The reason for the delay is either by concerned stakeholders or unavailability of materials in the market or ambitious schedule. Delay by contractor seems dominant in the context of Nepal and matches to irrigation project too. The major cause of delay in construction is the contractor and WUA. Overall 61\% of respondents believe that contractors and WUA cause a delay while $31 \%$ believe that unavailability of construction materials is the main cause for delay in construction.

During the design process availability of construction materials should be considered for planning and estimation of quantity. Otherwise, this issue needs to be addressed by the process of design review. Mishra and Aithal, 2021 [3] referred from Change Orders in Construction Projects in Saudi Arabia that the causes of delay by contractors are change of plan by owners, the substitution of materials, errors, and omissions in design, and owners' financial problems.

\subsubsection{Consideration of Operation and Maintenance in Design of Schemes:}

Operation and maintenance start after completion of the construction phase of the project. It is very important in FMIS because it has to be done by local resources with local manpower. If these parameters are included during the design phase that creates an easy and farmer-friendly operation and maintenance system. Most of the stakeholders agreed that the operation and maintenance issues need to be considered during the design phase. Most of the respondents claim that operation and maintenance are considered during the design of small irrigation schemes. Overall, $80 \%$ agree on the fact while $20 \%$ deny this. This indicates that a farmer-managed irrigation system is sustainable because of consideration of operation and maintenance during the design stage. Yoder (1994) [10] stated that it is important to know who will manage the operation and maintenance in selecting among alternative designs. In Nepal, the Modernization of Farmer Managed Irrigation should be made considering Factors Affecting Efficient Construction Project Design Development through further studies [20, 21, and 22].

\section{CONCLUSION :}

The participatory approach has been adopted right from the selection to surveying as well as designing the irrigation schemes. With the provision of a ceiling in cost for implementation, the designing agency could not address fully the required design aspects. Limitations in duration for selection to design irrigation schemes affect the satisfaction of beneficiaries. Priorities for use of local materials have been given to make cost-effectiveness and sustainability of the system along with ease for future maintenance. Redesign as per location and estimate of quantity is the most common issue to be followed in the design despite the repetitions in the type of system. Thus, project duration requirement of systems depends upon the location and type of structure required in the proposed system. The major causes of design review are technical issues followed by a change in local parameters. Apart from technical issues, social factors also contribute to design parameters, which need to be well-coordinated with beneficiaries.

From a combined questionnaire survey and case study it has been found that frequently changed components in the inner Terai region are headworks and canal lining works which need to focus during the design review. Stakeholders believe that design change may extend time and cost but hypothesis testing based on secondary data shows that design review can be done without time and cost extension. This occurs due to resource optimization at the proper time which is the core of value engineering. The design review process supports for sustainability and efficiency of schemes and is appropriate just after submission of the design report to clients. Generally, it seems hard to maintain a construction schedule and this delay occurs mainly due to a lack of coordination of construction activities between contractor and WUA. The design review process supports establishing positive relationships among stakeholders. Effective design and review process could contribute to change in cropping pattern while increasing cropping intensity as well as crop yield.

Design review has been necessitated due to the limited duration available for survey, design, and estimation. In addition, a review of farmers' requirements to make the subprojects economically as well 
as socially beneficial there is needed to review the design. The current practice of design review by the client was found to be in the preliminary stage in small irrigation schemes. An effective system of design review by the client is needed for cost-effective and sustainable design.

\section{RECOMMENDATION :}

The study should be continued for digging the significant factors affecting and effects of design review of selected irrigation projects.

\section{LIMITATIONS OF STUDY :}

(i) The study has not been focused to analyze the causes of design change of small-scale irrigation projects.

(ii) It has not been focused to study the effects of design review and its necessity.

(iii) The study focused on small-scale surface irrigation projects conducted DoLIDAR/ CIP Unit in Dang valley only for the study.

\section{REFERENCES :}

[1] NPC, (2015). Fourteenth sectoral Policy. Kathmandu: National Planning Commission. Available at www.npc.gov.np

[2] DoI, 2006. Guidelines for Irrigation Systems in Hills and Valleys. Jawalakhel: Department of Irrigation Government of Nepal Ministry of Irrigation. Available at www.doi.gov.np

[3] Mishra, A. K., \& Aithal, P. S. (2022). Causes and Effects of Design Change of Construction Projects. International Journal of Applied Engineering and Management Letters (IJAEML), 6(1), 87-99. DOI: https://doi.org/10.5281/zenodo.6085346.

Google Scholar $\chi^{\top}$

[4] Wisney, C. J. \& Walter, M. F., (1985). Small Scale Irrigation: Design Issues in Government Assisted Systems. Department of Agricultural Engineering.

[5] Singh, D.B., Pande, P.R. \& Pandey, D., 2015. Farmer Managed Irrigation Systems of Nepal: Key Elements for Their Sustainable O\&M. Small Scale Irrigation Systems: Challenges to Sustainable Livelihood, pp.47-62.

[6] DoI, (2014). Design Review Report: Badkapath Irrigation Project. Jawalakhel: Department of Irrigation.

[7] ADB, (2013). Project Administration Manual. Manila: Asian Development Bank. Available at https://www.adb.org/sites/default/files/project-document/175445/46535-001-pam.pdf

[8] DoLIDAR, (2013). Feasibility Assessment Report for Hanumaanpur Mulkulo Irrigation Sub Project. Harihar Bhawan: Department of Local Infrastructure Development and Agricultural Road. Available at https://doli.gov.np

[9] Jacob, S. B. (1995). Hill Irrigation Engineering with Special Emphasis on Planning, Design and Implementation of Farmer Hill Systems. New Delhi: IOE/Ford Foundation. https://lib.icimod.org/record/4202 Retrieved on 20/01/2022.

[10] Yoder, R. (1994). Suggestions for the Design Process. Colombo: International Irrigation Management Institute. https://publications.iwmi.org/pdf/H015392_Chapter_1.pdf

[11] PDSP, (1990). M.1 General System Planning. Kathmandu: Sir M MacDonald and Partners Ltd.in association with MacDonald Agricultural Services P. Ltd and East Consult P. Ltd. Department of Irrigation. $\quad$ https://www.wecs.gov.np/storage/listies/January2021/river-training-manual-final-wecs-2020-06-15-(f)-(1).pdf

[12] ADB, (2008). Final Report: Earthquake and Tsunami Emergency Support Project. Manila: Asian Development Bank. https://www.adb.org/projects/documents/earthquake-and-tsunamiemergency-support-project

[13] Sharma, K. R. \& Shukla, A., (1997). Participatory Irrigation Management in Nepal: A Monograph 
on Evolution, Processes and Performance. Jawalakhel: Department of Irrigation.

[14] Abernethy, C. L. (2015). Can Programs of Irrigation Management Transfer be Completed Successfully? Trajectory of Farmer Managed Irrigation Systems, p.77.

[15] UN, (1979). Guidelines for rural central planning. New York: United Nations Economic and Social Commission for Asia and Pacific. https://digitallibrary.un.org/record/168029

[16] Adhikari, B. R. \& Basnet, S. K. (2007). Rehabilitation of Praganna Kulo Irrigation Systems: Inputs of Farmers in Design. Irrigation in Transition: Interacting with Internal and External Factors and Setting the Strategic Actions, p.202.

[17] Mishra A. K, Magar, B. R. (2017). Implementability of Municipal Transport Master Plan of Bandipur Inner Ring Road, Tanahu. Nepal. International Journal of Scientific \& Technology Research, 6(8), 306-313.

Google Scholar X

[18] Mahadik, U. A. (2015). Value Engineering for Cost Reduction and Sustainability in Construction Projects. IOSR Journal of Mechanical and Civil Engineering, 1(1), 95-97.

Google Scholar X'

[19] Mishra, A. K., (2019). Implementation Status of Value Management in Project Management Practice in Nepal. International Journal of Management Studies, 6(1), 2231-2528.

Google Scholar ${ }^{\top}$

[20] Rezania, A. R., Sharifpour, M., Meshkizadeh, M. \& Zibanchi, M. H. (2011). Optimization of the Design of Irrigation and Drainage Networks Using Value Engineering-Case Study: Jofeir Irrigation and Drainage network, South West of Iran. ICID 21st International Congress on Irrigation and Drainage, pp.15-23.

[21] Singh, A. M. (2010). Modernization of Farmer Managed Irrigation Systems in Nepal. Hydro Nepal, $6(1), 56-60$.

Google Scholar 7

[22] Pandit, D. (2015). Factors Affecting Efficient Construction Project Design Development: A Perspective from India. International Journal of Construction Supply Chain Management, 5(1), 52-67.

Google Scholar $x^{\top}$ 